\title{
Does the sedation regimen affect adverse events during procedural sedation and analgesia in injection drug users?
}

\author{
Frank Xavier Scheuermeyer, MD, MHSc** Gary Andolfatto, $\mathrm{MD}^{\dagger}$; Hong Qian, $\mathrm{PhD}^{\ddagger}$; \\ Eric Grafstein, MD
}

ABSTRACT

Objectives: Injection drug users (IDUs) often undergo procedural sedation and analgesia (PSA) as part of emergency department (ED) treatment. We compared adverse events (AEs) using a variety of sedation regimens.

Methods: This was a retrospective analysis of a PSA safety audit in two urban EDs. Consecutive self-reported IDUs were identified, and structured data describing comorbidities, vital signs, sedation regimens (propofol [P], propofol-fentanyl $[P F]$, fentanyl-midazolam [FM], ketofol [1:1 ketamine:propofol, KF], and ketamine-propofol [KP]) and AEs were collected. The primary outcome was the proportion of patients in each sedation group having an $\mathrm{AE}$; the secondary outcome was the proportion of patients having a cardiovascular or respiratory $A E$.

Results: Data were collected on 276 IDUs (78 P, 82 PF, 65 FM, $25 \mathrm{KF}$, and $26 \mathrm{KP})$, and 18 patients had $\mathrm{AEs}(6.5 \%$, 95\% Cl 4.0 10.3). The AE rates were $0.0 \%, 8.5 \%, 9.2 \%, 12.0 \%$, and $7.6 \%$, respectively, with propofol having a significantly lower rate (Pearson coefficient 14.9, $p=0.007$ ). The cardiovascular/ respiratory $A E$ rates were significantly different as well, with $P$, $\mathrm{KP}$, and KF having the lowest rates (Pearson coefficient 13.3, $p$ $=0.01$ ).

Conclusions: For IDU PSA, the overall AE rate was $6.5 \%$, and propofol appeared to have a significantly lower rate.

\section{RÉSUMÉ}

Objectif: Les utilisateurs de drogues injectables (UDI) subissent souvent des interventions sous sédation-analgésie (SA) aux services des urgences. L'étude visait à comparer la fréquence des événements indésirables (EI) liés à la $S A$, administrée selon différents schémas posologiques.

\begin{abstract}
Méthode: Il s'agit d'une analyse rétrospective d'une vérification de l'innocuité de la SA dans deux services d'urgence situés en milieu urbain. Après le repérage de patients consécutifs qui se sont déclarés des UDI, il y a eu une collecte de données structurées sur les affections concomitantes, les signes vitaux, les schémas posologiques de sédatifs (propofol $[P]$, propofol-fentanyl [PF], fentanylmidazolam [FM], kétofol [kétamine-propofol $(1 / 1), K F]$, et kétamine-propofol [KP]) et les événements indésirables. Le principal critère d'évaluation était la proportion de patients dans chaque groupe de sédation qui avait connu des El; le critère d'évaluation secondaire consistait en la proportion de patients qui avait subi des El respiratoires ou cardiovasculaires.

Résultats: II y a eu collecte de données sur 276 UDI (78 P, 82 $\mathrm{PF}, 65 \mathrm{FM}, 25 \mathrm{KF}$, et $26 \mathrm{KP}$ ), et 18 patients ont connu des $\mathrm{EI}$ (6.5\%; IC à 95\% 4.0-10.3). Les taux d'El se sont établis comme suit: $0.0 \%, 8.5 \%, 9.2 \%, 12.0 \%$, et $7.6 \%$, respectivement; un taux significativement plus faible a été enregistré dans le groupe $\mathrm{P}$ (coefficient de corrélation de Pearson 14.9; $p=$ 0.007). Les taux $d^{\prime} E I$ respiratoires ou cardiovasculaires variaient considérablement aussi; les schémas $P, K P$, et $K F$ ont obtenu les taux les plus faibles (coefficient de corrélation de Pearson 13.3; $p=0.01$ ).

Conclusions: Le taux global d'EI liés à la SA chez les UDI s'élevait à $6.5 \%$, et le schéma $\mathrm{P}$ a semblé obtenir un taux sensiblement plus faible que les autres.
\end{abstract}

Keywords: marginalized populations, patient safety, procedural sedation and analgesia

Injection drug users (IDUs) frequently seek assistance in emergency departments (EDs) ${ }^{1-6}$ and occasionally

From the *Department of Emergency Medicine, St. Paul's Hospital and the University of British Columbia, Vancouver, BC; †Department of Emergency Medicine, Lions Gate Hospital and the University of British Columbia, North Vancouver, BC; łDepartment of Emergency Medicine, St Paul's Hospital and the University of British Columbia, Vancouver, BC and §Department of Emergency Medicine, Mount St. Joseph's Hospital and the University of British Columbia, Vancouver, BC.

Correspondence to: Dr. Frank Xavier Scheuermeyer, Department of Emergency Medicine, St. Paul's Hospital, 1081 Burrard Street, Vancouver, BC V6Z 1Y6; frank.scheuermeyer@gmail.com.

This article has been peer reviewed.

(c) Canadian Association of Emergency Physicians 
require painful treatments such as incision and drainage or fracture reduction, which necessitate procedural sedation and analgesia (PSA). Although IDUs appear to have a rate of adverse events (AEs) similar to that of non-IDUs, they require slightly higher doses of sedatives and analgesics and have longer recovery times. ${ }^{7}$

For PSA in the non-IDU population, there are many options: regimens such as propofol, propofol-fentanyl, fentanyl-midazolam, etomidate, or 1:1 ketamine:propofol have been studied; the $\mathrm{AE}$ rates and recovery times of these regimens are well known. However, IDUs may have different physiology than non-IDUs. Patients with chronic substance misuse may be sensitive to anesthetic agents ${ }^{8,9}$; furthermore, pain tolerance may be decreased, requiring increased analgesia. ${ }^{10-12}$ When comparing IDUs to non-IDUs, they are felt to have different tolerances for sedative and analgesic medications. ${ }^{13-16}$ PSA regimens that are safe and well tolerated in the non-IDU population may not be as successful in a patient who uses injection drugs. Currently, clinicians have little guidance in selecting a medication regimen that will allow safe and rapid sedation in the IDU population.

Our objective was to compare AEs and recovery times for a number of sedation regiments in a population of patients who use injection drugs and had PSA.

\section{METHODS}

\section{Study design}

This was a retrospective analysis of data prospectively collected for a safety audit on all patients undergoing PSA. Study methods have been fully explained in a previous publication comparing the safety of PSA in IDUs versus non-IDUs ${ }^{7}$ but are summarized below.

\section{Study setting and population}

The study was conducted from April 1, 2006, to January 31, 2009, in two urban Vancouver EDs. St. Paul's Hospital is an inner-city centre with 60,000 annual visits, and Mount St. Joseph's Hospital is a community site with 30,000 visits. Both are teaching hospitals staffed exclusively by emergency physicians, around one-quarter of whom work at both sites. The Ethics Committee of Providence Health Care, which oversees both sites, approved this study.

\section{Patient selection}

Both sites share a database that records all patient demographics, including age, gender, place of residence, mode of arrival, chief complaint, and admission and discharge times. All orders, including medications and consultations, are placed into this database. Emergency physicians complete discharge summaries on all patients, which record all diagnoses and procedures. All patients with "procedural sedation" were extracted from this database. Coding accuracy for a similar study involving electrical cardioversion for atrial fibrillation was estimated at $99 \% .{ }^{17}$

\section{Procedures}

Both sedation and procedure were typically performed by a single emergency physician and assisted by a registered nurse $(\mathrm{RN})$ and respiratory therapist $(\mathrm{RT})$ who had been specially trained in PSA. All patients were placed on a stretcher with continuous cardiac and oxygen monitors and intermittent blood pressure monitoring every 5 minutes or sooner, depending on the discretion of the physician or nurse. Procedures were started once patients had reached a dissociative or deep level of sedation. Physicians had discretion in selecting patients for PSA, administering preprocedural analgesia, selecting a sedation regimen, administering concurrent local or regional anesthesia, and deciding on post-PSA analgesia and follow-up. Patients were discharged once their modified Aldrete score ${ }^{18}$ was greater than 8 out of 10 .

\section{Data collection}

At the time of sedation, patients were required to have standardized data collected on special forms. The nurse recorded patient comorbidities, body weight, American Society of Anesthesiologists (ASA) risk score, and the last solid and liquid intake. IDU status was determined by the standardized question, "Have you used injection drugs in the past month?" prior to sedation. This approach was pioneered by the Vancouver Injection Drug Use Study ${ }^{1,4,6,19,20}$ and, although self-reported, appears to be accurate. ${ }^{21}$ The IDU status was recorded in a box on the data collection sheet, along with the patient's drug of choice (cocaine, heroin or other narcotic, or methamphetamine). All sedative and 
analgesic medications were recorded, along with dose and time. Vital signs were recorded at the start and finish of the procedure, whenever a medication was given, and every 5 minutes after the procedure was complete until the patient was suitable for discharge. AEs (see below) were recorded in detail, along with any intervention by the physician, $\mathrm{RN}$, or RT.

\section{Data abstraction}

The methods of Gilbert and colleagues ${ }^{22}$ and Worster and colleagues ${ }^{23}$ were followed, and three reviewers (two residents and a staff physician) independently reviewed the patient chart and sedation sheet. All patients with a discharge summary code of "procedural sedation" were scrutinized, and those deemed to be IDUs were included. Several lines of evidence were used to determine this ${ }^{1}$; most importantly, the IDU status was recorded on the sedation sheet. ${ }^{2}$ The full electronic medical record from 1999 (the start of electronic charting at our institutions) to the ED visit was scrutinized. ${ }^{3}$ Given that the vast majority of the IDU population lives in a wellcircumscribed urban area, the postal code of each patient was obtained. In case the status was unclear-for example, a patient who denied IDU but had a nondominant forearm abscess- the case was referred to two referees who were blinded to all outcomes: an internist with addiction specialization and an infectious disease physician with human immunodeficiency virus (HIV) specialization. The principal investigator determined the status if the referees disagreed.

Charts were scrutinized from 1999 up to the index ED visit to reconcile missing or conflicting information. A second blinded reviewer abstracted $10 \%$ of the charts, and interobserver reliability was calculated for the dichotomous elements of IDU status and ambulance arrival; this reviewer also reviewed all patients with an AE. Missing, conflicting, or unclear data were resolved by consensus at regular meetings.

\section{Outcome measures}

The primary outcome was the proportion of patients having an $\mathrm{AE}$ in each sedation group. AEs (Table 1) were defined by regional guidelines ${ }^{24}$ and included airway obstruction, apnea, or hypoxia; hypotension; recovery agitation (dysphoric behavior, shouting, or agitation) or myoclonus; and nausea or emesis. Additional AEs included use of reversal agents, recovery time exceeding

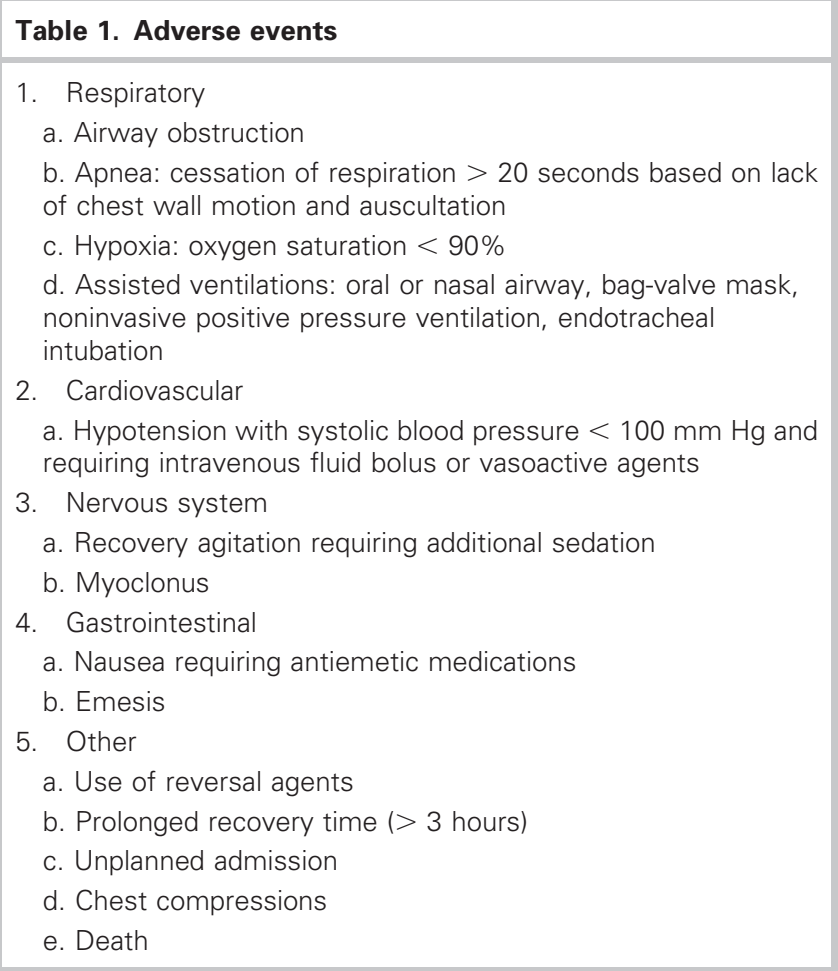

3 hours, and an unplanned hospital admission. Patients could have more than one AE; for example, an apneic patient might require a reversal agent as well. The secondary outcome was the proportion of patients in each group who had a cardiovascular or respiratory $\mathrm{AE}$ because these could be more "serious" than events such as nausea or a mild allergic reaction. Additional secondary outcomes included the recovery, sedation, and administration times. (Once a patient had a score of 8 out of 10 on the modified Aldrete scale, he or she was considered "recovered" from sedation.) Recovery time was defined as the time from the last medication administration to recovery; sedation time was defined as the time from the first medication administration to recovery; and administration time was defined as the time from first medication administration to last medication administration.

\section{Data analysis}

Data are reported as means with standard deviations for normally distributed data and medians with interquartile range (IQR) for non-normally distributed data. $\mathrm{AE}$ rates for the different sedation regimens were compared by a generalized Fisher exact test; the Kruskal-Wallis test (with 4 degrees of freedom) was used to compare recovery, sedation, and length-of-stay 
times. (We did not use tests of comparison for baseline variables as a rough inspection revealed no obvious outliers.) Tests of comparison were performed in R. scatterplots generated with Excel 2008 (Microsoft Inc., Richmond, WA), and boxplots were created using the "boxplot" command in R.

\section{RESULTS}

There were 2,584 procedural sedations during the study period, and data were collected on 276 consecutive
IDUs. Thirty-three (12.0\%) patients had missing weights, and $36(13.0 \%)$ patients had missing ASA classifications. Kappa values were 0.83 for IDU status and 0.90 for ambulance arrival. Ten patients required specialist adjudication to determine IDU status. Table 2 depicts baseline demographics for each of the five sedation regimens, indicating that cocaine and heroin (or other narcotics) were equally common. The overall population had a substantial rate of patients with abnormal initial vital signs $(39 \%$ had a heart rate $>100$ beats/min, $11 \%$ had systolic blood pressure

\begin{tabular}{|c|c|c|c|c|c|}
\hline Category & $\mathrm{P}(n=78)$ & $\mathrm{PF}(n=82)$ & $\mathrm{FM}(n=65)$ & $\mathrm{KP}(n=25)$ & $\mathrm{KF}(n=26)$ \\
\hline Age, mean (SD) & $37.0(9.9)$ & $37.1(9.6)$ & $36.5(8.8)$ & $35.5(7.4)$ & $37.1(9.8)$ \\
\hline Gender, $n$ ( $\%$ male) & $46(59.0)$ & $50(61.0)$ & $39(60.0)$ & $16(64.0)$ & $18(69.2)$ \\
\hline EMS arrival, $n(\%)$ & $27(34.6)$ & $39(47.6)$ & $23(35.3)$ & $13(52.0)$ & 7 (26.9) \\
\hline Patients at SPH & 70 (89.8) & 75 (91.5) & 61 (93.9) & $20(80.0)$ & $22(84.6)$ \\
\hline Patients at MSJ & $8(10.2)$ & 7 (8.5) & $4(6.2)$ & $5(20.0)$ & $4(15.4)$ \\
\hline \multicolumn{6}{|l|}{$\begin{array}{l}\text { Vital signs at the start of procedures, } \\
\text { mean (SD) }\end{array}$} \\
\hline Systolic blood pressure (mm Hg) & $120.3(16.5)$ & $122.5(17.0)$ & $120.2(19.0)$ & $121.3(17.3)$ & $122.8(12.4)$ \\
\hline Diastolic blood pressure $(\mathrm{mm} \mathrm{Hg})$ & $71.8(11.5)$ & $73.1(11.4)$ & $72.1(11.5)$ & $75.0(10.4)$ & $76.0(10.3)$ \\
\hline Heart rate (beats/min) & $98.2(18.0)$ & $96.2(16.0)$ & $93.9(15.2)$ & $95.8(12.6)$ & $92.1(17.8)$ \\
\hline Respiratory rate (breaths/min) & $18.5(2.3)$ & $18.2(2.3)$ & $18.1(1.8)$ & $18.8(3.4)$ & $18.5(2.1)$ \\
\hline Oxygen saturation (\%) & $97.6(1.1)$ & $97.9(1.2)$ & $97.4(1.2)$ & $97.3(2.1)$ & $98.5(1.1)$ \\
\hline Temperature $\left({ }^{\circ} \mathrm{C}\right)$ & $37.1(0.8)$ & $37.1(0.8)$ & $37.2(0.7)$ & $37.0(0.5)$ & $37.0(0.7)$ \\
\hline \multicolumn{6}{|l|}{$\begin{array}{l}\text { Patients with abnormal vital signs at the } \\
\text { start of procedures, } n(\%)\end{array}$} \\
\hline Systolic blood pressure $<100$ mm Hg & $10(12.8)$ & $9(11.0)$ & $12(18.4)$ & $5(20.0)$ & $3(11.5)$ \\
\hline Diastolic blood pressure $<60 \mathrm{~mm} \mathrm{Hg}$ & $11(14.1)$ & 7 (8.5) & 8 (12.3) & $3(12.0)$ & $3(11.5)$ \\
\hline Heart rate $>100$ beats/min & $31(39.7)$ & $30(36.6)$ & $28(43.0)$ & $14(56.0)$ & $8(30.8)$ \\
\hline Temperature $>37.5^{\circ} \mathrm{C}$ & $13(16.7)$ & $15(18.3)$ & $13(20.0)$ & $3(12.0)$ & $4(15.4)$ \\
\hline \multicolumn{6}{|l|}{ Drugs of abuse, $n(\%)^{*}$} \\
\hline Heroin & $38(48.7)$ & $37(45.1)$ & $29(44.6)$ & $14(56.0)$ & $11(42.3)$ \\
\hline Cocaine & $32(41.0)$ & $35(42.7)$ & $28(43.1)$ & $11(44.0)$ & $15(57.7)$ \\
\hline Amphetamines & $8(10.2)$ & $10(12.2)$ & $6(9.2)$ & $2(8.0)$ & $0(0.0)$ \\
\hline \multicolumn{6}{|l|}{ Comorbidities, $n(\%)$} \\
\hline HIV & $13(16.7)$ & $17(20.1)$ & $12(18.5)$ & $4(16.0)$ & $4(15.4)$ \\
\hline Hepatitis C & $40(51.3)$ & $44(53.7)$ & $43(66.1)$ & $13(52.0)$ & $14(53.5)$ \\
\hline \multicolumn{6}{|l|}{ ASA class, $n(\%)$} \\
\hline 1 & $51(65.4)$ & $55(67.0)$ & $43(66.1)$ & $17(68.0)$ & $20(76.9)$ \\
\hline 2 & $15(19.2)$ & $17(20.7)$ & $12(18.4)$ & $3(12.0)$ & $2(7.7)$ \\
\hline 3 & $2(2.6)$ & $2(2.4)$ & $0(0.0)$ & $0(0.0)$ & $1(3.8)$ \\
\hline 4 or 5 & $0(0.0)$ & $0(0.0)$ & $0(0.0)$ & $0(0.0)$ & $0(0.0)$ \\
\hline Not recorded & $10(12.8)$ & $8(9.8)$ & $10(15.4)$ & $5(20.0)$ & $3(11.5)$ \\
\hline \multicolumn{6}{|l|}{$\begin{array}{l}\text { ED opioid analgesia given }<30 \text { min prior } \\
\text { to PSA, } n(\%)\end{array}$} \\
\hline Morphine & $16(20.5)$ & $17(20.7)$ & $13(20.0)$ & $6(24.0)$ & $5(19.2)$ \\
\hline Fentanyl & $7(9.0)$ & $9(11.0)$ & 7 (2.9) & $5(20.0)$ & $2(7.7)$ \\
\hline
\end{tabular}


$<100 \mathrm{~mm} \mathrm{Hg}$, and $20 \%$ had a temperature $>37.5^{\circ} \mathrm{C}$ [>99.5 $\left.\left.{ }^{\circ} \mathrm{F}\right]\right)$. A total of $244(88.4 \%)$ patients had incision and drainage of a cutaneous abscess.

Dosing for each of the five sedation regimens was as follows (given in median [IQR]): propofol: $2.24 \mathrm{mg} / \mathrm{kg}$ (1.43-2.86 $\mathrm{mg} / \mathrm{kg})$; propofol-fentanyl: propofol $2.03 \mathrm{mg} / \mathrm{kg}(1.47-2.67 \mathrm{mg} / \mathrm{kg})$, fentanyl $1.30 \mu \mathrm{g} / \mathrm{kg}(0.88-1.62 \mu \mathrm{g} / \mathrm{kg})$; fentanyl-midazolam: fentanyl $3.10 \mu \mathrm{g} / \mathrm{kg}(2.14-5.00 \mathrm{mg} / \mathrm{kg})$, midazolam $0.05 \mathrm{mg} / \mathrm{kg}$ (0.03-0.08 mg/kg); ketamine-propofol: ketamine $0.55 \mathrm{mg} / \mathrm{kg}(0.43-1.19 \mathrm{mg} / \mathrm{kg})$, propofol $1.76 \mathrm{mg} / \mathrm{kg}(1.20-3.23 \mathrm{mg} / \mathrm{kg})$; and 1:1 single-syringe ketamine:propofol ("ketofol"): ketamine $0.89 \mathrm{mg} / \mathrm{kg}$ $(0.52-1.46 \mathrm{mg} / \mathrm{kg})$, propofol $0.89 \mathrm{mg} / \mathrm{kg}(0.52-1.46 \mathrm{mg} / \mathrm{kg})$.
Table 3 summarizes AEs. Eighteen patients (6.5\%, 95\% CI 4.0-10.3) had a total of $22 \mathrm{AEs}$. These AE rates were statistically dissimilar (Pearson coefficient 14.9, $p=$ 0.007), with propofol having the lowest rate. No patients died or required chest compressions or endotracheal intubation. Overall, 10 patients $(3.6 \%, 95 \%$ CI 0.9-6.8) had a cardiovascular or respiratory event, with those receiving propofol-fentanyl and fentanyl-midazolam having five events each; patients receiving the other three regimens had none. This difference was statistically significant (Pearson coefficient 13.2, $p=0.01$ ).

Table 4 details the 18 patients who had an AE, along with patient demographics, drug of choice, the procedure, all medications received, and a description

\begin{tabular}{|c|c|c|c|c|c|c|}
\hline Category & $\mathrm{P}(n=78)$ & $\operatorname{PF}(n=82)$ & $\mathrm{FM}(n=65)$ & $\mathrm{KP}(n=25)$ & $\mathrm{KF}(n=26)$ & Total $(N=276)$ \\
\hline \multicolumn{7}{|l|}{$\begin{array}{l}\text { Adverse events, } \\
n(\%, 95 \% \mathrm{Cl})\end{array}$} \\
\hline $\begin{array}{l}\text { Patients with } \\
\text { an } \mathrm{AE}^{\dagger}\end{array}$ & $0(0,0-3.8)$ & $7(8.5,3.8-17.4)$ & $6(9.3,3.8-19.6)$ & $3(12.0,3.2-32.3)$ & $2(7.7,13.4-26.6)$ & $18(6.5,4.0-10.3)$ \\
\hline Number of AEs & $0(0,0-3.8)$ & $8(9.7,4.6-18.8)$ & $9(13.9,6.9-25.2)$ & $3(12.0,3.2-32.3)$ & $2(7.7,13.4-26.6)$ & $22(8.0,5.1-12.0)$ \\
\hline $\begin{array}{l}\text { Number of } \\
\text { patients with } \\
\text { cardiovascular/ } \\
\text { respiratory } \mathrm{AE}^{\ddagger}\end{array}$ & $0(0,0-3.8)$ & $5(6.1,2.3-14.2)$ & $5(7.7,2.9-17.8)$ & $0(0,0-12.0)$ & $0(0,0-11.5)$ & $10(3.6,1.9-6.8)$ \\
\hline \multicolumn{7}{|l|}{ Respiratory } \\
\hline $\begin{array}{l}\text { Airway } \\
\text { obstruction }\end{array}$ & $0(0,0-3.8)$ & $0(0,0-3.7)$ & $0(0,0-4.6)$ & $0(0,0-12.0)$ & $0(0,0-11.5)$ & $0(0,0-1.1)$ \\
\hline Apnea & $0(0,0-3.8)$ & $1(1.2,0.06-7.6)$ & $2(3.1,0.5-11.7)$ & $0(0,0-12.0)$ & $0(0,0-11.5)$ & $3(1.1,0.3-3.4)$ \\
\hline Hypoxia & $0(0,0-3.8)$ & $1(1.2,0.06-7.6)$ & $2(3.1,0.5-11.7)$ & $0(0,0-12.0)$ & $0(0,0-11.5)$ & $3(1.1,0.3-3.4)$ \\
\hline \multicolumn{7}{|l|}{ Cardiovascular } \\
\hline Hypotension & $0(0,0-3.8)$ & $3(3.7,1.0-11.1)$ & $1(1.5,0.08-9.4)$ & $0(0,0-12.0)$ & $0(0,0-11.5)$ & $4(1.5,0.5-3.9)$ \\
\hline \multicolumn{7}{|l|}{ Nervous system } \\
\hline $\begin{array}{l}\text { Recovery } \\
\text { agitation }\end{array}$ & $0(0,0-3.8)$ & $0(0,0-3.7)$ & $0(0,0-4.6)$ & $1(4.0,0.2-22.3)$ & $2(7.7,13.4-26.6)$ & $3(1.1,0.3-3.4)$ \\
\hline Myoclonus & $0(0,0-3.8)$ & $0(0,0-3.7)$ & $0(0,0-4.6)$ & $0(0,0-12.0)$ & $0(0,0-11.5)$ & $0(0,0-1.1)$ \\
\hline \multicolumn{7}{|l|}{ Gastrointestinal } \\
\hline Nausea & $0(0,0-3.8)$ & $0(0,0-3.7)$ & $0(0,0-4.6)$ & $0(0,0-12.0)$ & $0(0,0-11.5)$ & $0(0,0-1.1)$ \\
\hline Emesis & $0(0,0-3.8)$ & $0(0,0-3.7)$ & $0(0,0-4.6)$ & $1(4.0,0.2-22.3)$ & $0(0,0-11.5)$ & $1(0.3,0.02-2.3)$ \\
\hline \multicolumn{7}{|l|}{ Other } \\
\hline $\begin{array}{l}\text { Use of reversal } \\
\text { agent }\end{array}$ & $0(0,0-3.8)$ & $1(1.2,0.06-7.6)$ & $3(4.6,1.2-13.8)$ & $0(0,0-12.0)$ & $0(0,0-11.5)$ & $4(1.5,0.5-3.9)$ \\
\hline $\begin{array}{l}\text { Prolonged } \\
\text { recovery time }\end{array}$ & $0(0,0-3.8)$ & $2(2.4,0.4-9.4)$ & $2(3.1,0.5-11.7)$ & $1(4.0,0.2-22.3)$ & $0(0,0-11.5)$ & $4(1.5,0.5-3.9)$ \\
\hline $\begin{array}{l}\text { Unplanned } \\
\text { admission }\end{array}$ & $0(0,0-3.8)$ & $0(0,0-3.7)$ & $0(0,0-4.6)$ & $0(0,0-12.0)$ & $0(0,0-11.5)$ & $0(0,0-1.1)$ \\
\hline $\begin{array}{l}\text { Chest } \\
\text { compressions }\end{array}$ & $0(0,0-3.8)$ & $0(0,0-3.7)$ & $0(0,0-4.6)$ & $0(0,0-12.0)$ & $0(0,0-11.5)$ & $0(0,0-1.1)$ \\
\hline Death & $0(0,0-3.8)$ & $0(0,0-3.7)$ & $0(0,0-4.6)$ & $0(0,0-12.0)$ & $0(0,0-11.5)$ & $0(0,0-1.1)$ \\
\hline
\end{tabular}




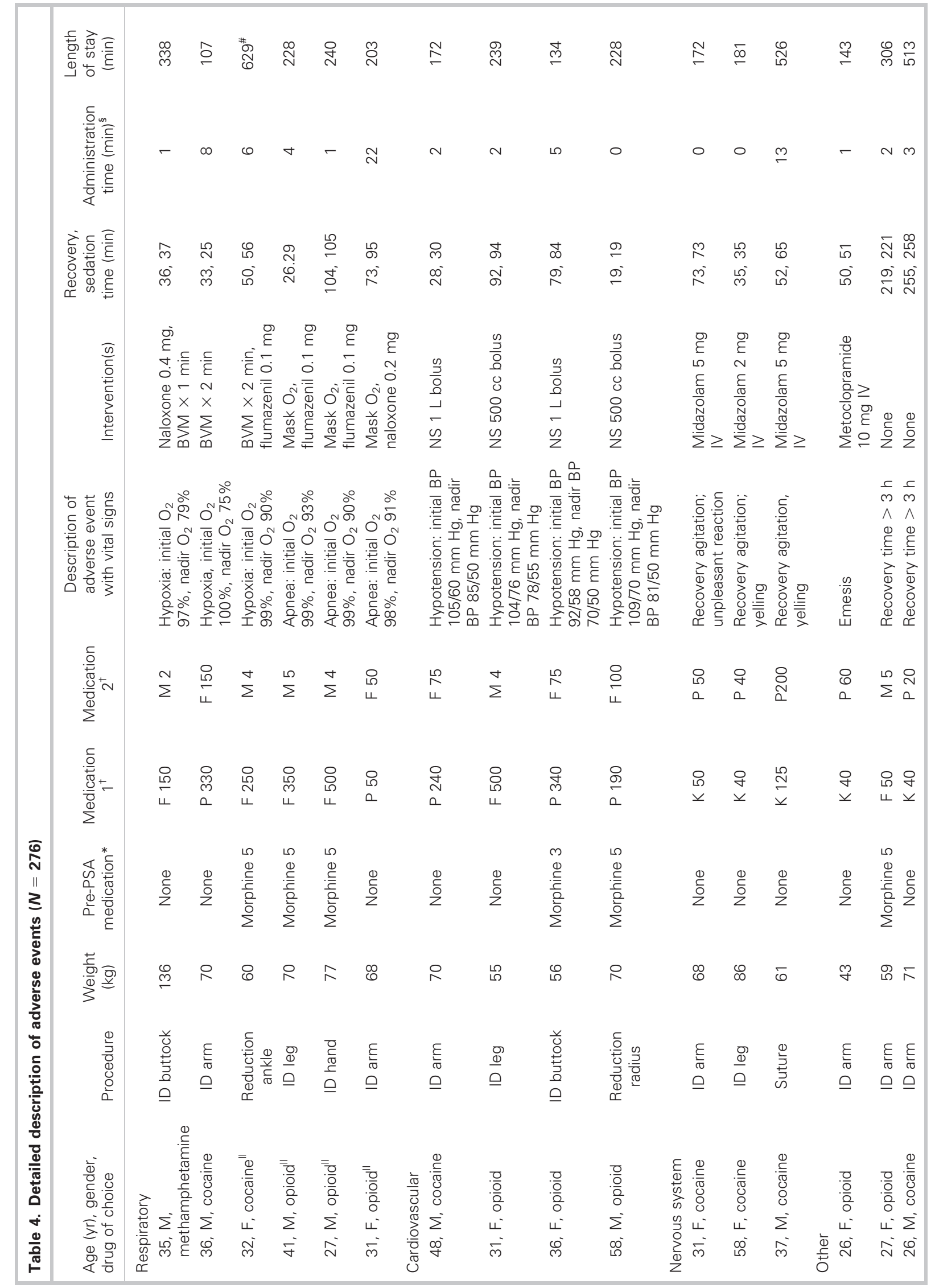


of the $\mathrm{AE}$, along with all interventions. Recovery, sedation, and administration times are included, as well as length of stay and disposition.

The median administration time of patients who had an AE was 2.5 minutes; (IQR 1-5.5 minutes) of the 18, 3 had a time of less than 1 minute, 3 took 1 minute, 3 took 2 minutes, and 2 took 3 minutes. For patients having an $\mathrm{AE}$, median recovery times were 52 minutes (IQR 34-190 minutes) and median sedation times were 65 minutes (IQR 34-193 minutes).

Regardless of drug choice (cocaine, heroin, methamphetamines), $\mathrm{AE}$ rates appeared to be similar. AE rates were 8 of $125(6.4 \%), 9$ of $126(7.1 \%)$, and 1 of 24 $(4.2 \%)$, respectively, whereas cardiovascular/respiratory $\mathrm{AE}$ rates were 3 of 125 (2.4\%), 6 of 127 (4.7), and 1 of 24 (4.2\%), respectively. Neither the overall AE rate (Pearson coefficient $0.26, p=0.88$ ) nor the cardiovascular/ respiratory $\mathrm{AE}$ rates (Pearson coefficient $0.93, p=$ $0.63)$ were significantly different between the groups. Three patients who used cocaine became agitated after ketamine administration.

Other outcomes are illustrated in Table 5. The median overall recovery time was 19 minutes, and the groups appeared to be similar ( $\mathrm{H}$ statistic $8.63, p=$ $0.07)$. The median overall sedation time was 25 minutes, and the groups appeared to be dissimilar $(\mathrm{H}$ statistic $15.9, p=0.003$ ), with propofol having the shortest sedation time. The difference between the sedation and recovery times implies that a median of 6 minutes (IQR 3-9 minutes) was used to administer medications.

\section{DISCUSSION}

In a cohort of 276 patients who use injection drugs and received $\mathrm{ED} \mathrm{PSA}, 6.5 \%$ of patients had an $\mathrm{AE}$, with propofol $(0.0 \%)$ having a significantly lower $\mathrm{AE}$ rate. The finding that 78 patients receiving propofol had no AEs, whereas 82 patients receiving propofol-fentanyl had seven, echoes the findings of both Messenger and collegues $^{25}$ and Miner and colleagues, ${ }^{26}$ although these studies were randomized trials that defined AEs differently. Patients who received fentanyl-midazolam or propofol-fentanyl had significantly higher rates of cardiovascular and respiratory events than patients who received the other three regimens, underscoring the contention that neither of these sedation regimens may be considered as "safe" as propofol alone in this population. 


\begin{tabular}{|c|c|c|c|c|c|c|}
\hline Category & $\mathrm{P}(n=78)$ & $\operatorname{PF}(n=82)$ & $\mathrm{FM}(n=65)$ & $\mathrm{KP}(n=25)$ & $\mathrm{KF}(n=26)$ & Total $(N=276)$ \\
\hline \multicolumn{7}{|l|}{ Times, median (IQR) } \\
\hline Recovery time (min) & $15(10-29)$ & $15(8-33)$ & $23(12-57)$ & $17(7-44)$ & $23(13-38)$ & $19(10-38)$ \\
\hline Sedation time (min) & $23(15-33)$ & $30(18-41)$ & $35(20-60)$ & $25(15-54)$ & $30(20-45)$ & $25(15-45)$ \\
\hline \multicolumn{7}{|l|}{ ED disposition } \\
\hline Patients discharged from ED, $n(\%)$ & $65(83.3)$ & $72(87.8)$ & $53(81.5)$ & $21(84.0)$ & $21(80.7)$ & $232(84.1)$ \\
\hline Admitted to hospital, $n(\%)$ & $13(16.7)$ & $10(12.2)$ & $12(18.5)$ & $4(16.0)$ & $5(19.2)$ & $44(15.9)$ \\
\hline
\end{tabular}

Another finding relates not to the type of patient, the patient's drug of choice, or the sedation regimen but the fact that patients who had AEs had very short administration times; the median time was substantially shorter for patients having AEs (2.5 minutes) than those who did not have AEs (6 minutes). Given the occasionally large doses of sedative and analgesics required, this rapid administration may have played a role in the resultant AE. The strategy of starting at a low initial dose and then gradually titrating medications may be associated with a lower rate of AEs.

Reduction of AEs is desirable not only for patient safety but also for resource use. Patients having AEs had substantially longer median recovery (52 versus 19 minutes) and sedation (63 versus 25 minutes) times than the group as a whole.

In our institutions, procedural sedation is typically performed in "fast-track" areas, which are designed to have rapid patient turnover but little patient monitoring and a high patient to nurse ratio. In these areas, PSA is the most resource-intensive procedure performed, and avoiding AEs could result in decreased physician, nursing, and RT time, as well as quickly freeing the monitoring equipment for other patients.

Although patients who use specific drugs might be expected to have certain reactions (e.g., administering ketamine to cocaine users has been reported to precipitate arrhythmias and pulmonary edema ${ }^{27}$ ), there was little statistical correlation between the choice of drug (cocaine, opiates, or amphetamines) and AEs or prolonged recovery times, although the small sample sizes may have been a factor. For example, three cocaine-using patients became very agitated after ketamine sedation; ketamine appears to increase direct central nervous system and cardiac stimulation by inhibiting norepinephrine uptake, resulting in increased plasma catecholamines. ${ }^{28}$ Caution may be advised in administering ketamine to patients with a history of cocaine abuse.

Although there was no statistical difference in recovery time, and propofol appeared to have a statistically shorter sedation time than the other regimens, this emphasizes that propofol alone is at least as rapid as the other regimens, while leading to a very low rate of AEs.

Although this was a retrospective evaluation of IDUs, it assists clinicians by 1) demonstrating that the $\mathrm{AE}$ rate appears to be low and that no patients required admission or died due to an $\mathrm{AE} ; 2$ ) identifying that the choice of sedation regimen may influence the $\mathrm{AE}$ rate, with propofol having the lowest rate; 3) demonstrating that fentanyl-midazolam and propofolfentanyl have a significantly higher rate of cardiovascular and respiratory AEs; 4) showing that a rapid administration time may be implicated in many AEs; and 5) illustrating that propofol appears to have a short recovery and significantly shorter sedation time than the other regimens. Based on these findings, propofol sedation appears to be very safe and rapid in the IDU population.

\section{LIMITATIONS}

Several factors reduce the generalizability of this study. IDU status was self-reported, and the treating physicians, nurses, and respiratory therapists, as well as data abstractors, were aware of this. Self-administered patient analgesia prior to ED presentation-especially involving illicit narcotics that could affect sedationwas not recorded. Some of the groups (e.g., the ketofol and ketamine-propofol groups and the cohort of methamphetamine users) were small, and this may make comparisons difficult or lead to spurious, nonsignificant differences that might be significant in a larger group. Dosing by weight was omitted for the 
$10 \%$ of patients who did not have weights recorded. Choice of sedative and analgesic medications was physician dependent, and variability in dose and timing could affect AEs, recovery and sedation times, and length of stay. Use of local or regional anesthesia was individualized and not consistently recorded.

Standardized AE tools such as the Quebec criteria ${ }^{29}$ were published after most of the data had been collected. Some AEs, such as minor airway adjustments, may not have been recorded, and this likely lowered the proportion of patients with an $\mathrm{AE}$ in each group. Our region did not mandate capnography until after study completion; this may have lowered the number of AEs in each group as well. ${ }^{30}$ Physician and patient satisfaction scores were not recorded. To confirm the above findings, ideally, a prospective trial with rigorously defined prespecified AEs would be conducted.

\section{CONCLUSION}

For IDU PSA, the overall AE rate was $6.5 \%$, and propofol appeared to have a significantly lower rate.

Competing interests: None declared.

\section{REFERENCES}

1. Palepu A, Tyndall MW, Leon H, et al. Hospital utilization and costs in a cohort of injection drug users. CMAJ 2001; 165:415-20.

2. World drug report. Volume 1. Analysis. New York: United Nations Office on Drugs and Crime; 2004.

3. Gordon RJ, Lowy FD. Bacterial infections in drug users. $N$ Engl 7 Med 2005;353:1945-54, doi:10.1056/NEJMra042823.

4. Fairbairn N, Milloy MJ, Zhang R, et al. Emergency department utilization among a cohort of HIV-positive injecting drug users in a Canadian setting. 7 Emerg Med 2012. [Epub June 28, 2011]

5. Hope V, Kimber J, Vickerman P, et al. Frequency, factors, and costs associated with injection site infections: findings from a national multi-site survey of injecting drug users in England. BMC Infect Dis 2008;8:120, doi:10.1186/14712334-8-120.

6. Kerr T, Wood E, Grafstein E, et al. High rates of primary care and emergency department use among injection drug users in Vancouver. I Public Health (Oxf) 2005;27:62-6, doi:10.1093/pubmed/fdh189.

7. Scheuermeyer F, Andolfatto G, Lange L, et al. Do injection drug users have more adverse events during procedural sedation and analgesia for incision and drainage of cutaneous abscesses? CFEM 2012. DOI:10.2310/8000.2012.120710.

8. May JA, White HC, Leonard-White A, et al. The patient recovering from alcohol or drug addiction: special issues for the anesthesiologist. Anesth Analg 2001;92:1601-8, doi:10. 1097/00000539-200106000-00050.

9. Kuczkowski KM. Anesthetic implications of drug abuse in pregnancy. 7 Clin Anesth 2003;15:382-94, doi:10.1016/ S0952-8180(03)00056-4.

10. Hay JL, White JM, Bochner F, et al. Hyperalgesia in opioidmanaged and opioid-dependent patients. I Pain 2009;10: 316-22, doi:10.1016/j.jpain.2008.10.003.

11. Kreek MJ. Cocaine, dopamine, and the endogenous opioid system. F Addict Dis 1996;15:73-96, doi:10.1300/J069v 15n04_05.

12. Hall EP, Henry JA. Illicit drugs and surgery. Int 7 Surg 2007; 5:365-70, doi:10.1016/j.ijsu.2006.06.006.

13. Silverman SM. Opioid induced hyperalgesia: clinical implications for the pain practitioner. Pain Phys 2009;12:679-84.

14. Mehta V, Langford RM. Acute pain management for opioid dependent patients. Anaesthesia 2006;61:269-76, doi:10. 1111/j.1365-2044.2005.04503.x.

15. Richebe P, Beaulieu P. Perioperative pain management in the patient treated with opioids: continuing professional development. Can 7 Anaesth 2009;56:969-81, doi:10.1007/ s12630-009-9202-y.

16. Huxtable CA, Roberts LJ, Somogyi AA, MacIntyre PE. Acute pain management in opioid-tolerant patients: a growing challenge. Anesth Intensive Care 2001;39:804-23.

17. Scheuermeyer F, Grafstein E, Stenstrom R, et al. Thirty day outcomes of emergency department patients undergoing electrical cardioversion for atrial fibrillation or flutter. Acad Emerg Med 2010;17:418-15.

18. Aldrete JA. The post-anesthesia score revisited. 7 Clin Anesth 1995;7:89-91, doi:10.1016/0952-8180(94)00001-K.

19. Wood E, Tyndall MW, Spittal PM, et al. Unsafe injection practice in a cohort of injection drug users in Vancouver: could safer injecting rooms help? CMA7 2001;165:405-10.

20. Kerr T, Stoltz J-A, Tyndall M, et al. Impact of a medically supervised safer injection facility on community drug use patters: a before and after study. BMF 2006;332:220-2, doi:10.1136/bmj.332.7535.220.

21. Mensch BS, Kandel DB. Underreporting of substance use in a national longitudinal youth cohort: individual and interviewer effects. Public Opin Q 1988;52:100-24, doi:10.1086/ 269084.

22. Gilbert EH, Lowenstein SR, Kozoil-McLain J, et al. Chart reviews in emergency medicine research: where are the methods? Ann Emerg Med 1996;27:305-8, doi:10.1016/ S0196-0644(96)70264-0.

23. Worster A, Bledsoe RD, Cleve P, et al. Reassessing the methods of medical record review studies. Ann Emerg Med 2005;45:448-51, doi:10.1016/j.annemergmed.2004.11.021.

24. Willman EV, Andolfatto G. A prospective evaluation of "ketofol" (ketamine/propofol combination) for procedural sedation and analgesia in the emergency department. Ann Emerg Med 2007;49:23-30, doi:10.1016/j.annemergmed. 2006.08.002.

25. Messenger DW, Murray HE, Dungey PE, et al. Subdissociative-dose ketamine versus fentanyl for analgesia during propofol procedural sedation: a randomized clinical trial. Acad Emerg Med 2008;15:877-86, doi:10.1111/j.15532712.2008.00219.x. 
26. Miner JR, Gray RO, Stephens D, et al. Randomized clinical trial of propofol with and without alfentanil for deep procedural sedation in the emergency department. Acad Emerg Med 2009; 16:825-34, doi:10.1111/j.1553-2712.2009.00487.x.

27. Murphy JL. Hypertension and pulmonary edema associated with ketamine administration in a patient with a history of substance abuse. Can 7 Anaesth 1993;40:160-4, doi:10.1007/ BF03011314.

28. Stoelting RK. Pharmacology and physiology in anesthetic practice. 2nd ed. Philadelphia: JB Lippincott; 1991.
29. Bhatt M, Kennedy RM, Osmond MH, et al. Consensusbased recommendations for standardizing terminology and reporting adverse events for emergency department procedural sedation and analgesia in children. Ann Emerg Med 2009;53:426-35.e4, doi:10.1016/j.annemergmed.2008. $\underline{09.030 .}$

30. Burton JH, Harrah JD, Germann CA, et al. Does end-tidal carbon dioxide monitoring detect respiratory events prior to current sedation monitoring practices? Acad Emerg Med 2006;13:500-4, doi:10.1111/j.1553-2712.2006.tb00999.x. 